\title{
The antitumor effect of sulforaphane on Ehrlich solid mass tumor is associated with a reduction in the expression of plectin protein and oxidative stress
}

\author{
Esraa Elden R. Beltagy ${ }^{1 *}$, Tarek K. Abou Zed ${ }^{1}$, Nasr E. Nasr ${ }^{1}$, Enas A. Nosser ${ }^{2}$, Wafaa M. Ibrahim³ ${ }^{3}$ Khaled A. Kahilo ${ }^{1}$ \\ ${ }^{1}$ Department of Biochemistry, Faculty of Veterinary Medicine, Kafrelsheikh University, Egypt. \\ ${ }^{2}$ Department of Biochemistry, Faculty of Veterinary Medicine, Aswan University, Egypt. \\ ${ }^{3}$ Department of Medical Biochemistry, Faculty of Medicine, Tanta University, Egypt.
}

\section{ARTICLE INFO \\ Received on: 14/06/2018 \\ Accepted on: 14/10/2018 \\ Available online: 30/11/2018}

Key words:

Sulforaphane, Ehrlich solid tumor, DNA fragmentation, plectin, oxidative stress.

\begin{abstract}
Background/Objective: Although cabbage and its sulforaphane (Sul) contents have chemo-preventive effect against cancer, little attention was given to their mechanism of action. Therefore, this study was conducted to investigate the effect of Sulforaphane (Sul) on Ehrlich's solid tumor in mice.

Methods: Mice were randomly divided into the following six groups (15 mice each): the normal control group (Nor), the Ehrlich group (E), the Sul-treated groups on day $0[\mathrm{E}+\mathrm{Sul}(0)]$ and on day $7[\mathrm{E}+\mathrm{Sul}(7)]$ orally received Sul $(50 \mathrm{mg} / \mathrm{kg}$ ), methotrexate (MTX)-treated groups on day 0 [E + MTX (0)] and day 7 [E + MTX (70)] injected intraperitoneally by MTX $(1.25 \mathrm{mg} / \mathrm{kg})$, on day 0 and day 7 of Ehrlich tumor cells implantation.

Results: Our results revealed antitumor effect for Sul via, at least in part, induction of apoptosis (revealed by increased DNA fragmentation and decreased expression of the apoptotic modulator plectin) and reduction of oxidative stress (indicated by low level of lipid peroxidation marker, Malondialdehyde, and high level of total antioxidant capacity in tumor tissue). Administration of Sul at day 0 of Ehrlich xenografts gave better results than when giving 7 days postxenografting, but both effects were weaker than that of the standard anticancer drug, MTX.

Conclusion: This may be the first study to report that Sul antitumor effect is associated with downregulation of the apoptosis regulatory protein, plectin. The results of this study suggest that Sul could be used as an adjuvant to anticancer drug or as a chemopreventive agent against cancer.
\end{abstract}

\section{INTRODUCTION}

Cancer is the second leading cause of death worldwide (Klaunig et al., 2011; Lima et al., 2016). Throughout our life, we are often exposed to wide range of carcinogenic agents; which may be endogenous (immunologic disturbances genetics, endocrine imbalance) or exogenous factors (physical, environment, chemical or biologic agents, nutrition, and lifestyle) (Béliveau and Gingras, 2007).

The use of natural or synthetic compounds (i.e., chemopreventive agents) for the prevention of cancer has been described

\footnotetext{
"Corresponding Author

Esraa Elden R. Beltagy, Department of Biochemistry,

Faculty of Veterinary Medicine, Kafrelsheikh University, Egypt.

E-mail: genecom3@yahoo.com; Vet_esraarisk@yahoo.com
}

(Abdelwahab et al., 2018; Azaam et al., 2018; Badawy et al., 2018; Cheung and Kong, 2010; Elgazar et al., 2018). Cruciferous vegetables are one such family containing chemo-protective substances. Previous studies suggest that intake of cruciferous vegetable reduces overall cancer risk, especially during the early stages and increasing its intake provides protection at all stages of carcinogenesis (Clarke et al., 2008; Joseph et al., 2004). Cabbage (Brassica oleracea) is one of the cruciferous vegetable families (Rokayya et al., 2013). In addition to using it as a food, cabbage was used for medicinal purposes in headaches, gout, diarrhea, and peptic ulcers treatment (Singh et al., 2006). Many research studies have focused on the beneficial effects of cabbage phytochemicals, especially its indole-3-carbinole (I3C), sulforaphane (Sul), and indoles (Brooks et al., 2001). Cabbage content of Sulforaphane (Sul) ranged around $7.58 \mu \mathrm{g} / \mathrm{g}$ DW and its ideal dose is $0.1-0.5 \mathrm{mg} / \mathrm{kg}$ in mice (Campas-Baypoli et al., 2009). Sul can act via several mechanisms that suppress cancer progression. 
It plays an important role against oxidative stress (Rokayya et al., 2013; Singh et al., 2006), it inhibits histone deacetylases (HDACs) (Kim et al., 2016), it also has a role in the induction of apoptosis and cell cycle arrest (Wang et al., 2014), and it influences transcriptional factors and cellular signaling (Bhamre et al., 2009).

Ehrlich solid tumor was chosen as the experimental model of carcinogenesis. It is a neoplasm of epithelial origin, corresponding to murine mammary adenocarcinoma. This tumor is easily cultivated and transferred in vivo and can be used to study the mechanisms of carcinogenesis and evaluate the effect of new therapeutic approaches for tumors (El-Magd et al., 2017; Khamis et al., 2018; Verçosa Junior et al., 2007).

Plectin is one of the largest polypeptides known, it is about 4,684 amino acids and $\geq 500 \mathrm{kDa}$ (Liu et al., 1998). It is the most versatile cytoskeletal linker protein known (Wiche, 1998). Its major function is the maintenance of cytoarchitecture (Sonnenberg and Liem, 2007) as it plays a vital role in the organization of cytoskeleton network, viscoelastic properties, and mechanical integrity of the cytoplasm and the cells and tissues resistance (Wiche, 1998). Plectin, as a substrate of the apoptotic marker caspase 8 , is needed for the reorganization of the microfilament system during apoptosis (Beil et al., 2002) and so it can act as an apoptotic modulator.

Much attention was given to chemo-preventive mechanisms of broccoli and its Sul contents, while cabbage, another Brassicaceae member which also has considerable content of Sul and other beneficial phytochemicals, received little attention in terms of its chemo-preventive mechanisms. Therefore, this study was conducted to investigate the effect of Sul on Ehrlich's solid tumor with special focus on the role of plectin protein.

\section{MATERIALS AND METHODS}

\section{Reagents and extraction of Sul}

Methotrexate (MTX) was purchased from Sanofi (Cairo, Egypt). Malondialdehyde (MDA) and total antioxidant capacity (TAC) kits of the biochemical assays were purchased from BioDiagnostic Medical Company (Egypt). Sul was extracted and its concentration was determined as previously described (El-Keey et al., 2017). Briefly, air-dried plant material was ground and the obtained powder $(0.5 \mathrm{~g})$ was hydrolyzed in $7 \mathrm{ml} \mathrm{HCl} \mathrm{pH} 3.0$ at $37^{\circ} \mathrm{C}$ for 12 hours and then the supernatant was extracted with $5 \mathrm{ml}$ dichloromethane trice. After salting with sodium sulphate anhydrous and dehydration by a rotary evaporator at $30^{\circ} \mathrm{C}$, the obtained fraction was dissolved in $2 \mathrm{ml}$ of $20 \% \mathrm{v} / \mathrm{v}$ acetonitrile and injected to $10 \mathrm{~cm} \times 2.5 \mathrm{~cm}$ silica solid-phase extraction column. Following washing with ethyl acetate, the sulforaphane was eluted by dichloromethane and its concentration was measured by spectrophotometer at $240 \mathrm{~nm}$ maximum wavelength $\left(\lambda_{\max }\right)$ and $950 \mathrm{M}^{-1} \mathrm{~cm}^{-1}$ molar attenuation coefficient $(\varepsilon)$. Sul was detected by GC-MS using Perkin Elmer Clarus 580 Gas chromatograph, followed by checking the mass spectrum of the extracted sulforaphane in MAINLIB library.

\section{Xenograft tumor model (solid Ehrlich carcinoma)}

A model of solid Ehrlich carcinoma (SEC) was developed, where a total number of $2 \times 10^{6}$ Ehrlich carcinoma cells obtained from the Pharmacology and Experimental Oncology
Unit of the National Cancer Institute (NCI, Cairo University, Egypt) were subcutaneously implanted into the right thigh of the hind limb of mice. A palpable solid tumor mass (about $100 \mathrm{~mm}^{3}$ ) developed within 12 days.

\section{Animals \& experimental design}

Female Swiss albino mice $(n=90$, age $37 \pm 1.25$ day, weighing about 20-25 g) were housed in wire mesh cages and were fed standard mice diet and allowed free access to water. They were kept under the following environmental conditions [temperature $\left(24 \pm 2^{\circ} \mathrm{C}\right)$, relative humidity $(55 \% \pm 3 \%)$, and light (12 hours light/dark cycles)] and a 7 days adaptation period was permitted before beginning the experiment. All experiments were carried out according to the guidelines of the ethical committee of Kafrelshiekh University, Faculty of Veterinary Medicine.

Mice were randomly divided into the following groups (15 mice each):

- The normal control group (Nor) included untreated mice.

- Ehrlich group (E) included mice subcutaneously implanted by Ehrlich tumor cells.

- The Sul-treated group on day $0[\mathrm{E}+\mathrm{Sul}(0)]$ contained mice received $1.5 \mathrm{mg}$ Sul dissolved in $25 \mu \mathrm{l}$ saline $(50 \mathrm{mg} / \mathrm{kg})$ orally by stomach gavage once daily on day 0 after subcutaneous implantation of Ehrlich tumor cells and continued for 1 month.

- Sul-treated group on day $7[\mathrm{E}+\mathrm{Sul}(7)]$ was similar to group V but Sul was given 7 days after subcutaneous implantation of Ehrlich tumor cells.

- MTX-treated group on day $0[\mathrm{E}+\mathrm{MTX}(0)]$ contained mice injected intraperitoneally by MTX $(1.25 \mathrm{mg} / \mathrm{kg}$, every 48 hours for 2 weeks) and subcutaneously by Ehrlich tumor cells on the same day.

- MTX-treated group on day 7 [E + MTX (70)] was similar to group III but MTX was administered 7 days after subcutaneous implantation of Ehrlich tumor cells.

\section{Sampling}

At the end of the experiment, the animals were sacrificed under a slight ether anesthesia by cervical dislocation and blood samples were taken into a dry sterile centrifuge tube allowed to clot at room temperature for 30 minutes, and then centrifuged for 10 minutes at 5,000 rpm. Sera were separated and stored in aliquots at $-80^{\circ} \mathrm{C}$ until used. Tumors were carefully dissected excluding any muscular tissue, then they were weighed, dimensions measured and washed three times with cold-ice PBS and chilled on ice. Each tumor was divided into three pieces and stored at $-80^{\circ} \mathrm{C}$ until further use.

\section{DNA fragmentation}

The genomic DNA was extracted from normal muscle and tumor tissue samples using Gene JET genomic DNA extraction kit following the manufacturer's protocol (Fermentas, \#K0721, European Union). Followed by, agarose gel electrophoresis (2\%) to detect DNA fragmentation. The fragment patterns (ladder, smear, or intact) were visualized on the UV Trans-illuminator 
and photographed by gel documentation system (UVDI Major Science, USA). All samples were processed at once, to avoid differences due to the extraction process itself.

\section{Determination of total antioxidant capacity}

This was done using total antioxidant capacity colorimetric assay kit supplied by Bio-Diagnostic, Egypt. Normal muscle and tumor tissue samples were soaked in PBS ( $\mathrm{pH} 7.4$ ) containing $0.16 \mathrm{mg} / \mathrm{ml}$ heparin to remove any red blood cells and clots, then it was homogenized in $5 \mathrm{ml}$ cold buffer $(50 \mathrm{mM}$ potassium phosphate, $\mathrm{pH}$ 7.5). The homogenate was then centrifuged at 4,000 rpm for 15 minutes, and the supernatant was carefully collected. For the blank test, the sample was replaced with distilled water. Total antioxidant concentration (nmol/g tissues) was calculated as follows: (sample absorbance-blank absorbance) $\times 3.33$ (as per kit recommendations).

\section{Determination of lipid peroxidation marker, malondialdehyde}

Normal muscle and tumor tissue samples were processed as in the previous step, and MDA levels were detected by using lipid peroxidation colorimetric assay kit supplied by Bio-Diagnostic, Egypt and as previously described (El-Magd et al., 2017). The absorbance of the sample was read against a blank (distilled water) and against + the standard (provided in the kit) at $534 \mathrm{~nm}$ wavelength. Calculations were set as per kit recommendations:

MDA in Tissue

$$
\begin{aligned}
& =(\text { A sample } / \text { A standard }) \times(10 / \mathrm{g} . \text { tissue used }) \\
& =\text { nmol } / \mathrm{g} \text { tissue }
\end{aligned}
$$

\section{Western blotting}

Assessment of plectin protein (as an apoptotic marker) was evaluated by western blot as previously described (Alzahrani et al., 2018; El-Magd et al., 2018). In brief, the normal muscle and tumor tissue samples were homogenized in RIPA lysis buffer with Complete $^{\mathrm{TM}}$, Mini Protease Inhibitor Cocktail (Roche, USA), and then cell lysates were centrifuged at $15,000 \mathrm{rpm} / 20$ minutes $/ 4^{\circ} \mathrm{C}$. The supernatants were collected carefully to new tubes on ice. Total protein contents were determined by using the Folin Lowry method followed by protein separation by $12 \%$ SDS-PAGE and transfer to nitrocellulose membrane (Millipore, Bedford, USA). After washing and blocking with 3\% skimmed milk powder in TBS-T (TBS $+0.1 \%$ Tween-20), the membranes were incubated with primary antibodies; anti-plectin antibody (1:500, Abcam, Cat. no. ab83497) overnight with gentle rocker-shaking followed by washing and incubation with the secondary antibody $(1: 5,000$ in blocking solution, rabbit anti-Mouse IgG HRP-conjugated, Abcam, \# ab6728) for 1 hour at room temperature. Protein bands were visualized using TMB solution at room temperature for 15 minutes, or until protein bands became clearly visible. The densitometry analysis of protein bands was carried out using Image $\mathrm{J}$ software, and the density of each band was normalized to that of $\beta$-actin (1:500, Abcam, Cat. no. ab8226).

\section{Statistical analysis}

All the data were expressed as a mean \pm standard error of mean (SEM). The statistical significance was evaluated by oneway analysis of variance using SPSS, 18.0 software (SPSS Corp,
Chicago, IL), and individual comparisons were done by Duncan's multiple range test. Values were considered statistically significant when $p<0.05$.

\section{RESULTS}

\section{Effect of Sul on DNA fragmentation}

DNA isolated from normal control muscle tissue and Ehrlich solid tumor showed intact (non-degraded) bands near gel wells. In contrast, a variable degree of DNA fragmentation, revealed by DNA laddering and smearing, was noticed after administration of Sul or MTX. The most severe pattern of DNA fragmentation was observed in mice treated with MTX at day 0 , then Sul at day 0 followed by MTX at day 7 and finally Sul at day 7 groups (Fig. 1).

\section{Effect of Sul on lipid peroxidation (malondialdehyde)}

Highest significant level of MDA was observed in the tumor of Ehrlich group as compared to normal control group and other treated groups. The elevated MDA levels were significantly decreased following administration of Sul at day 0 and day 7 , with lowest level at day 0 (Fig. 2). On the other hand, Ehrlich group treated with MTX at day 0 and day 7 exhibited the lowest MDA levels and was not statistically different from the normal control group. Moreover, Ehrlich group treated with Sul at day 0 and MTX at day 7 did not show a significant difference in MDA levels.

\section{Effect of Sul on total antioxidant capacity}

Highest significant TAC levels were obtained in the normal control group, followed by Ehrlich group treated with MTX at day 0 , MTX at day 7, and Sul at day 0 then at day 7 (Fig. 2). On the other hand, Ehrlich group treated with Sul at day 0 or MTX at day 7 did not show any significant differences in TAC. The Ehrlich non-treated group showed the lowest TAC as compared to all other groups.

\section{Effect of Sul on plectin protein expression}

The change in relative expression of plectin protein was detected in Ehrlich solid tumor dissected from leg muscles of mice using western blot technique (Fig. 3). Expression of plectin protein was significantly increased in Ehrlich mice as compared to control and other treated mice. This elevated expression was significantly down-regulated following treatment with Sul at day 0 and day 7, with the best improvement obtained when Sul was given at day 0 of Ehrlich's injection. However, the declined plectin expression induced by Sul was still significantly below that of the standard anticancer drug MTX and the control (normal) mice. Additionally, the expression was significantly lower in MTX than in normal control mice. Interestingly, treatment at day 0 showed higher improvement than at day 7 in both Sul and MTX.

\section{DISCUSSION}

Several previous in vitro and in vivo studies denoted an antitumor effect for vegetables of Brassica genus of the Brassicaceae family, in particular, broccoli, cabbage, and cauliflower (Clarke et al., 2008; Joseph et al., 2004). Cabbage anticancer activity was mainly owed to its contents of indole-3carbinole (I3C), sulforaphane (Sul), and indoles phytochemicals (Brooks et al., 2001). Sul is known to suppress cancer progression through induction of apoptosis (Wang et al., 2014) and oxidative 


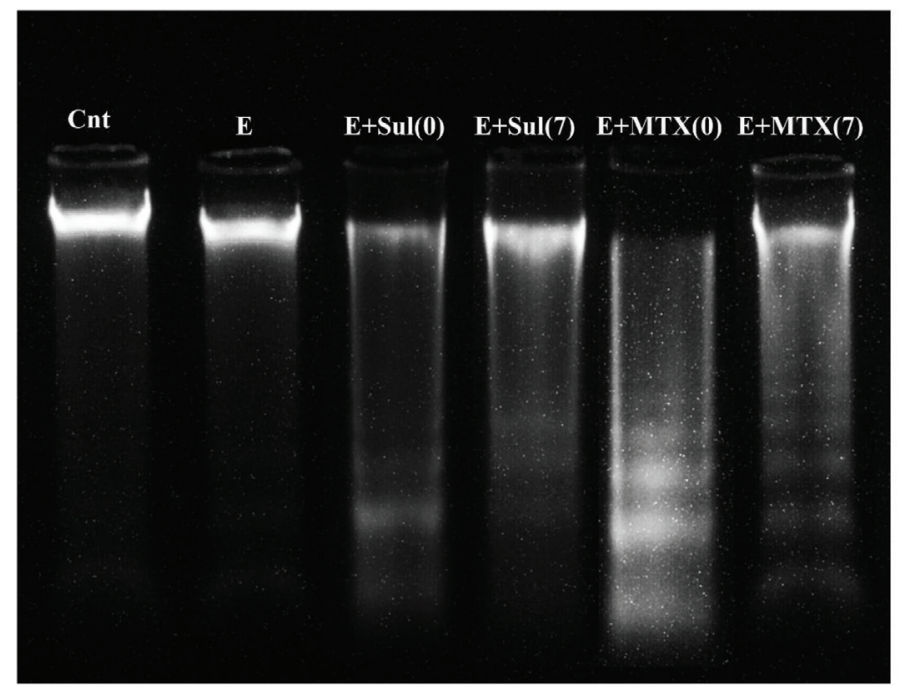

Figure 1. Ethidium bromide stained agarose gel showing the effect of Sul and methotrexate on DNA fragmentation in Ehrlich solid tumor. Each lane has five pooled DNA samples from each group. Cnt, normal control group; E, Ehrlich group; E + Sul (0) Ehrlich group treated by Sul at day 0; E + Sul (7), Ehrlich group treated by Sul at day 7; E + MTX (0), Ehrlich group treated by methotrexate at day 0; E + MTX (7), Ehrlich group treated by methotrexate at day 7 .

stress (Saha et al., 2012), however, the actual mechanism is still incompletely known. This prompts us to conduct this study to unveil how Sul exert its anticancer effect. Our results revealed anticancer effect for Sul via, at least in part, induction of apoptosis (as revealed by increased DNA fragmentation and decreased plectin protein expression) and reduction of oxidative stress (as indicated by the low level of MDA and the high level of TAC in tumor tissue). For the best of our knowledge, this may be the first study to report that Sul antitumor effect associated with downregulation of the apoptosis modulator protein, plectin.

The cancer cell maintains survival through inhibition of apoptosis and so an efficient anticancer drug/natural product should be a potent inducer to cancer cells apoptosis (El-Magd et al., 2017). The majority of previous studies have focused on the effect of Sul and other cabbage phytochemicals on the standard apoptotic pathways and showed activation of p53, p21, Bax, caspase 3, and downregulation of Bcl2 in a large variety of cancer cells (Bhamre et al., 2009; Devi and Thangam, 2012; Pappa et al., 2006; Wang et al., 2014). However, none of these previous studies investigated Sul effect on the cytoskeletal linker protein plectin, which is essential for maintenance of cytoarchitecture (Sonnenberg and Liem, 2007) and reorganization of the microfilament system during apoptosis (Stegh et al., 2000) as it acts as a substrate to the apoptotic marker caspase 8 (Beil et al., 2002). Subsequently, cancer cells will have an increased expression of this protein to keep themselves from cell death. Indeed, a previous report has found a significant upregulation for plectin in prostate cancer cell PC3-ML2 (Burch et al., 2013). This previous study also found that reduced plectin expression can inhibit PC3-ML2 cells proliferation, migration, and invasion. In agreement, our results also showed a significant increase in plectin expression in Ehrlich solid tumor tissues and a notable reduction following treatment by Sul. This suggests that Sul may induce apoptosis in cancer cells through, at least in part, inhibition of plectin. So the
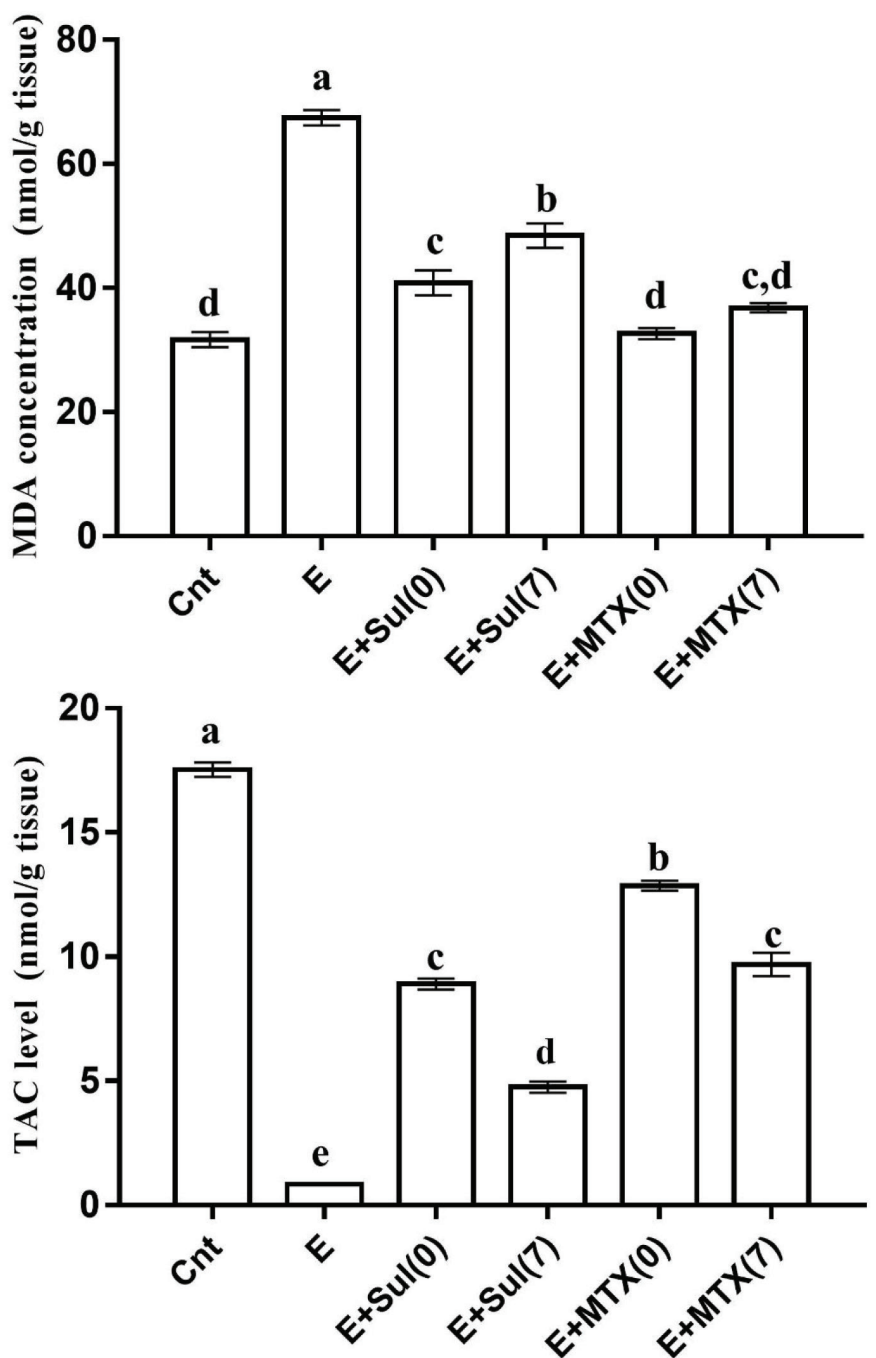

Figure 2. Effect of Sul on the level of MDA and TAC levels in Ehrlich solid tumor mice, in comparison to the standard anticancer drug MTX. Data expressed as mean $\pm \operatorname{SEM}(n=9$ from two separate experiments). Values with different letters were significantly different at $p \leq 0.05$.

question now is what is the actual role for plectin in apoptosis. Before answering this question, it is worth to know that apoptosis leads to disorganization and cleavage of cytoskeleton proteins (including myosin II, actin, intermediate filament, and microtubules) which subsequently cause morphological changes characteristic for apoptosis (Caulin et al., 1997). Hence, early loss of plectin, the main cytolinker and activator to these cytoskeletal proteins, may allow initiation of apoptosis process. Indeed, plectin is a downstream target for caspase 8-dependent apoptotic pathway (Beil et al., 2002; Stegh et al., 2000). Once this pathway activated by TNFR1, caspase 8 (in mitochondria) translocates to plectin (in cytoplasm) and cleaves it before any other cytoskeletal proteins (Stegh et al., 2000). As plectin seems to be a specific caspase 8 substrate (Stegh et al., 2000), it is likely that Sul may induce cancer cell death via activation of caspase 8 and its down-stream target plectin. Further molecular investigations are required to validate this possibility.

Another confirmation for induction of apoptosis in cancer cells was revealed by DNA fragmentation. Expectedly, Sul induced a notable DNA fragmentation in form of laddering which 
(A)

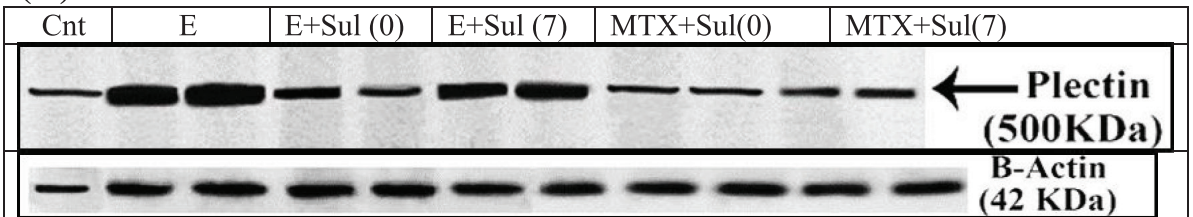

(B)

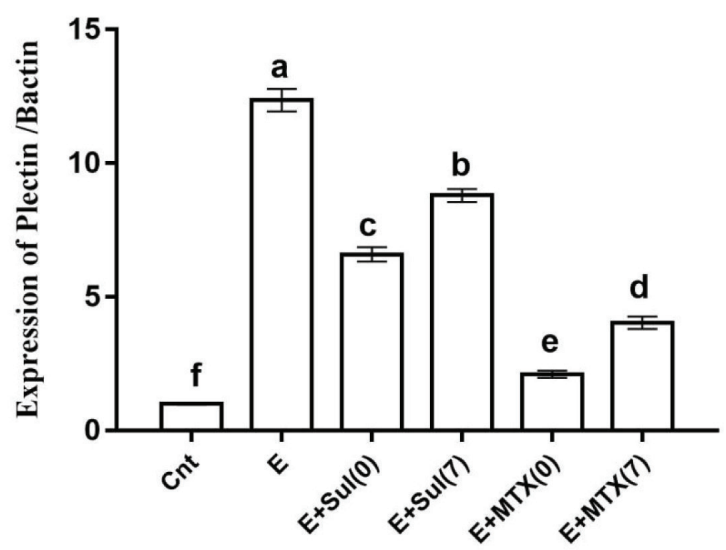

Figure 3. Effect of treatment by Sul (compared to MTX) on the expression of plectin protein in Ehrlich solid tumor xenografted in thigh muscles of mice. (A) The expression of plectin was detected by western blotting analysis in all groups. $\beta$-actin was used as a control for internal protein loading. (B) Band intensity revealed relative changes in plectin protein expression in all groups using the normal control (Cnt) as a basal line. Values were expressed as mean \pm SEM $(n=9$ from two separate experiments). Values with different letters are significantly different at $p \leq 0.05$.

is specific for apoptosis rather than necrosis. A similar effect for Sul and other cabbage phytochemicals was reported on variable tumor types by other studies (Bhamre et al., 2009; Cheung and Kong, 2010; Devi and Thangam, 2012; Pappa et al., 2006). However, this degradable effect on DNA may be independent on plectin, as DNA fragmentation was reported in plectin-deficient fibroblasts (Stegh et al., 2000).

Although we did not perform cell migration assay, other studies reported a positive association between overexpression of plectin, and its downstream target integrin $\beta 4$, and cell migration in prostate cancer cells (Burch et al., 2013; Yang et al., 2011). This effect can be explained on the basis that plectin and integrin $\beta 4$ are main components of the cell to cell junction complex (such as hemidesmosomes) that plays a crucial role in cell spreading (Watanabe and Akaike, 1999). Taken together, targeting plectin may be a new strategy to induce apoptosis in cancer cells and to prevent their metastasis.

Another mechanism by which anticancer agents can kill cancer cells is the inhibition of oxidative stress. Cabbage phytochemicals suppress cancer progression via inhibition of oxidative stress in cancer cells (Rokayya et al., 2013; Singh et al., 2006). In consistent with these findings, the results of the present study showed the ability of Sul to inhibit oxidative stress as evidenced by a significant decrease in the level of lipid peroxidation marker MDA and a significant increase in TAC in tumor tissues following administration of Sul.

Throughout this experiment, administration of Sul at day 0 of Ehrlich xenografts gave better results than when giving 7 days post-xenografting. This indicates the impact of Sul as a preventive, better than therapeutic, agent for Ehrlich solid tumor. On the other hand, the chemo-preventive and anticancer effect of
Sul was weaker than that of the standard anticancer drug, MTX, indicating that Sul may be used as either chemo-preventive agent or as an adjuvant to another anticancer drug, rather than a sole treatment.

\section{CONCLUSION}

For the best of our knowledge, this may be the first study to report that Sul anticancer effect is associated with reduced expression of the apoptosis modulator protein, plectin. Moreover, this anticancer effect was also accompanied by notable DNA fragmentation and lower oxidative stress. The chemopreventive effect of Sul was better than the chemotherapeutic effect. Hence, Sul could be used as a chemopreventive agent and any of its phytochemical can be used as an adjuvant for chemotherapy. However further evaluations thorough clinical trials are needed to confirm whether treatment by Sul is clinically relevant in human.

\section{LIST OF ABBREVIATIONS}

HDACs Histone deacetylasesMDA Malondialdehyde

MDA Malondialdehyde

MTX Methotrexate

SEC Solid Ehrlich carcinomaSul Sulforaphane

Sul Sulforaphane

TAC Total antioxidant capacity

\section{CONFLICT OF INTERESTS}

There are no conflicts of interest.

\section{FUNDING}

Nil. 


\section{REFERENCES}

Abdelwahab MA, El-Barbary AA, El-Said KS, Betiha M, Elkholy HM, Chiellini E, El-Magd MA. Functionalization of poly(3hydroxybutyrate) with different thiol compounds inhibits MDM2-p53 interactions in MCF7 cells. J Appl Polymer Sci, 2018; 46924; doi:10.1002/ app.46924

Alzahrani FA, El-Magd MA, Abdelfattah-Hassan A, Saleh AA, Saadeldin IM, El-Shetry ES, Badawy AA, Alkarim S. Potential effect of exosomes derived from cancer stem cells and MSCs on progression of DEN-induced HCC in rats. Stem Cells Int, 2018; 2018:17; doi:10.1155/2018/8058979

Azaam MM, Kenawy E-R, El-din ASB, Khamis AA, ElMagd MA. Antioxidant and anticancer activities of $\alpha$-aminophosphonates containing thiadiazole moiety. J Saudi Chem Soc, 2018; 22:34-41.

Badawy AA, El-Magd MA, AlSadrah SA. Therapeutic effect of camel milk and its exosomes on MCF7 cells in vitro and in vivo. Integr Cancer Ther, 2018; doi:10.1177/1534735418786000

Beil M, Leser J, Lutz MP, Gukovskaya A, Seufferlein T, Lynch G, Pandol SJ, Adler G. Caspase 8-mediated cleavage of plectin precedes F-actin breakdown in acinar cells during pancreatitis. Am J Physiol Gastrointest Liver Physiol, 2002; 282:G450-60.

Béliveau R, Gingras D. Role of nutrition in preventing cancer. Canadian Family Phys, 2007; 53:1905-11.

Bhamre S, Sahoo D, Tibshirani R, Dill DL, Brooks JD. Temporal changes in gene expression induced by sulforaphane in human prostate cancer cells. Prostate, 2009; 69:181-90.

Brooks JD, Paton VG, Vidanes G. Potent induction of phase 2 enzymes in human prostate cells by sulforaphane. Cancer Epidemiol Prevent Biomark, 2001; 10:949-54.

Burch TC, Watson MT, Nyalwidhe JO. Variable metastatic potentials correlate with differential plectin and vimentin expression in syngeneic androgen independent prostate cancer cells. PLoS One, 2013; 8:e65005.

Campas-Baypoli ON, Bueno-Solano C, Martinez-Ibarra DM, Camacho-Gil F, Villa-Lerma AG, Rodriguez-Nunez JR, Loez-Cervantes J, Sanchez-Machado DI. Sulforaphane (1-isothiocyanato-4-(methylsulfinyl)butane) content in cruciferous vegetables. Arch Latinoam Nutr, 2009; 59:95-100.

Caulin C, Salvesen GS, Oshima RG. Caspase cleavage of keratin 18 and reorganization of intermediate filaments during epithelial cell apoptosis. J Cell Biol, 1997; 138:1379-94.

Cheung KL, Kong A-N. Molecular targets of dietary phenethyl isothiocyanate and sulforaphane for cancer chemoprevention. AAPS J, 2010; 12:87-97.

Clarke JD, Dashwood RH, Ho E. Multi-targeted prevention of cancer by sulforaphane. Cancer Lett, 2008; 269:291-304.

Devi JR, Thangam EB. Mechanisms of anticancer activity of sulforaphane from Brassica oleracea in HEp-2 human epithelial carcinoma cell line. Asian Pac J Cancer Prev, 2012; 13:2095-100.

El-Keey MM, El Ghonamy MA, Ali TM, Ibrahim WM, Tousson E. Effect of sulforaphane and methotrexate combined treatment on histone deacetylase activity in solid ehrlich carcinoma. J Biosci Appl Res, 2017; 3:62-9.

El-Magd MA, Khamis A, Nasr Eldeen SK, Ibrahim WM, Salama AF. Trehalose enhances the antitumor potential of methotrexate against mice bearing Ehrlich ascites carcinoma. Biomed Pharmacother, 2017; 92:870-8.

El-Magd MA, Khalifa SF, A. Alzahrani FA, Badawy AA, El-Shetry ES, Dawood LM, Alruwaili MM, Alrawaili HA, Risha EF, El-Taweel FM, Marei HE. Incensole acetate prevents beta-amyloidinduced neurotoxicity in human olfactory bulb neural stem cells. Biomed Pharmacother, 2018; 105:813-23.

Elgazar AA, Selim NM, Abdel-Hamid NM, El-Magd MA, El Hefnawy HM. Isolates from Alpinia officinarum Hance attenuate LPS induced inflammation in $\mathrm{HepG} 2$ : evidence from in silico and in vitro studies. Phytother Res, 2018; (In Press).

Joseph MA, Moysich KB, Freudenheim JL, Shields PG, Bowman ED, Zhang Y, Marshall JR, Ambrosone CB. Cruciferous vegetables, genetic polymorphisms in glutathione S-transferases $\mathrm{M} 1$ and $\mathrm{T} 1$, and prostate cancer risk. Nutr Cancer, 2004; 50:206-13.
Khamis A, El-Magd MA, NasrEldeen SK, Ibrahim WM, Salama AF. Toxicity studies of trehalose and/or methotrexate in mice. Res J Pharm Biol Chem Sci, 2018; 9:83-9.

Kim E, Bisson WH, Lohr CV, Williams DE, Ho E, Dashwood RH, Rajendran P. Histone and non-histone targets of dietary deacetylase inhibitors. Curr Topics Med Chem, 2016; 16:714-31.

Klaunig JE, Wang Z, Pu X, Zhou S. Oxidative stress and oxidative damage in chemical carcinogenesis. Toxicol Appl Pharm, 2011; 254:86-99.

Lima JEA, Yamashita AS, Pimentel GD, De Sousa LG, Santos RVT, Gonçalves CL, Streck EL, Lira FS, Neto R, Cesar J. Doxorubicin caused severe hyperglycaemia and insulin resistance, mediated by inhibition in AMPk signalling in skeletal muscle. J Cachexia Sarcopenia Muscle, 2016; 7:615-25.

Liu X, Li P, Widlak P, Zou H, Luo X, Garrard WT, Wang X. The 40-kDa subunit of DNA fragmentation factor induces DNA fragmentation and chromatin condensation during apoptosis. Proc Nat Acad Sci, 1998; 95:8461-6.

Pappa G, Lichtenberg M, Iori R, Barillari J, Bartsch H, Gerhauser C. Comparison of growth inhibition profiles and mechanisms of apoptosis induction in human colon cancer cell lines by isothiocyanates and indoles from Brassicaceae. Mutat Res, 2006; 599:76-87.

Rokayya S, Li C-J, Zhao Y, Li Y, Sun C-H. Cabbage (Brassica oleracea L. var. capitata) phytochemicals with antioxidant and antiinflammatory potential. Asian Pac J Cancer Prevent, 2013; 14:6657-62.

Saha S, Hollands W, Teucher B, Needs PW, Narbad A, Ortori CA, Barrett DA, Rossiter JT, Mithen RF, Kroon PA. Isothiocyanate concentrations and interconversion of sulforaphane to erucin in human subjects after consumption of commercial frozen broccoli compared to fresh broccoli. Mol Nutr Food Res, 2012; 56:1906-16.

Singh J, Upadhyay A, Bahadur A, Singh B, Singh K, Rai M Antioxidant phytochemicals in cabbage (Brassica oleracea L. var. capitata) Sci Horticult, 2006; 108:233-7.

Sonnenberg A, Liem RK. Plakins in development and disease. Exp Cell Res, 2007; 313:2189-203.

Stegh AH, Herrmann H, Lampel S, Weisenberger D, Andra K, Seper M, Wiche G, Krammer PH, Peter ME. Identification of the cytolinker plectin as a major early in vivo substrate for caspase 8 during CD95- and tumor necrosis factor receptor-mediated apoptosis. Mol Cell Biol, 2000; 20:5665-79.

Verçosa Junior D, Melo M, Cassali G, Dantas-Barros A, Silva Junior P. Influence of Agaricus blazei Murrill in solid Ehrlich tumor and popliteal lymph nodes in mice. Arquivo Brasil Med Vet Zoot, 2007; 59:150-4.

Wang M, Zhu J-Y, Chen S, Qing Y, Wu D, Lin Y-M, Luo J-Z, Han W, Li Y-Q. Effects of co-treatment with sulforaphane and autophagy modulators on uridine 5'-diphospho-glucuronosyltransferase 1A isoforms and cytochrome P450 3A4 expression in Caco-2 human colon cancer cells. Oncol Lett, 2014; 8:2407-16.

Watanabe Y, Akaike T. Possible involvement of caspase-like family in maintenance of cytoskeleton integrity. J Cell Physiol, 1999; 179:45-51.

Wiche G. Role of plectin in cytoskeleton organization and dynamics. J Cell Sci, 1998; 111:2477-86.

Yang L, Nyalwidhe JO, Guo S, Drake RR, Semmes OJ. Targeted identification of metastasis-associated cell-surface sialoglycoproteins in prostate cancer. Mol Cell Proteomics, 2011; 10:M110.007294.

\section{How to cite this article:}

Beltagy EER, Abou Zed TK, Nasr NE, Nosser EA, Ibrahim WM, Kahilo KA. The antitumor effect of sulforaphane on Ehrlich solid mass tumor is associated with a reduction in the expression of plectin protein and oxidative stress. J Appl Pharm Sci, 2018; 8(11): 009-014. 